\title{
New Types of Behavioral Manipulation of Host Spiders by a Parasitoid Wasp
}

\author{
William G. Eberhard \\ Smithsonian Tropical Research Institute, Universidad de Costa Rica, Ciudad Universitaria, Costa Rica \\ Correspondence should be addressed to William G. Eberhard, william.eberhard@gmail.com
}

Received 14 October 2009; Revised 9 June 2010; Accepted 15 July 2010

Academic Editor: Robert Matthews

Copyright ( $) 2010$ William G. Eberhard. This is an open access article distributed under the Creative Commons Attribution License, which permits unrestricted use, distribution, and reproduction in any medium, provided the original work is properly cited.

\begin{abstract}
The larva of the parasitic wasp Zatypota sp. nr. solanoi induces its host spiders Anelosimus spp. to modify its web in ways not seen in normal webs of this species or in any other species, providing apparent protection and support for the wasp's cocoon by covering the entire web with a protective sheet and adding a central platform and opening a space below in the enclosed tangle, where the larva suspends its cocoon. These modifications differ qualitatively from those induced by a congeneric wasp. Parasitized spiders appeared to adjust modified web construction behavior to local conditions, implying that larval manipulations may occur at higher rather than lower levels of behavioral control (e.g., eliciting overall design decisions, rather than particular motor patterns).
\end{abstract}

\section{Introduction}

The behavior of some animals changes when they are parasitized. The possibility that such changes are adaptive for the parasite has been controversial, because some alterations may be incidental byproducts of the parasite's effects on its host [1]. Other changes, however, are well designed to promote the survival of the parasite, and are thought to represent manipulation of the host to the parasite's advantage [2-5].

Ichneumonid wasps in the tribe Polysphinctini are ectoparasites of spiders, $[6,7]$ and several species in the "Polysphincta clade" (hereafter "polysphinctine wasps") modify the web construction behavior of their hosts $[7,8]$. After growing slowly for a week or more as it feeds on the spider's hemolymph (and apparently not affecting its host's behavior), the larva induces the spider to build a modified, "cocoon" web. The larva then kills and devours its host, builds a cocoon attached to the cocoon web, and pupates. Cocoon webs built by spiders appear to improve the chances of survival of the wasp's cocoon [8-11]. Spiders never survive to reproduce once their behavior is altered, so cocoon web construction has probably evolved under selection on the larva rather than the spider.

Different wasp species show diverse and subtle effects on host behavior, and these effects consistently take advantage of particular features of the web designs of unparasitized spiders of the different hosts to provide protective structures for their cocoons. Modifications include reducing an orb web to a few highly reinforced radial lines $[8,12]$, reinforcing a tangle of lines next to the orb and adding a vestigial hub at its center from which to suspend the cocoon [9], reinforcing the frame and anchor lines of an orb and building a reduced, strengthened orb-like web within these frames and adding camouflage for the cocoon [13-15], building or reinforcing a small protected silk chamber for the cocoon in the host's web $[10,11]$, and simply omitting the orb next to a resistant tangle web [16].

The present study concerns the wasp Zatypota nr. solanoi (Ichneumonidae), which parasitizes the spiders Anelosimus nr. studiosus and A. octavius (Theridiidae). This rare species (1.1\% of the 374 A. octavius spiders sampled systematically were parasitized) induces still different behavioral changes; these changes are also adjusted to the biology and behavior of their hosts.

\section{Material and Methods}

Parasitized mature female spiders with an egg or larva on the abdomen were collected with their webs in early second growth in San Josè Province, at about $1500 \mathrm{~m}$ el. near 


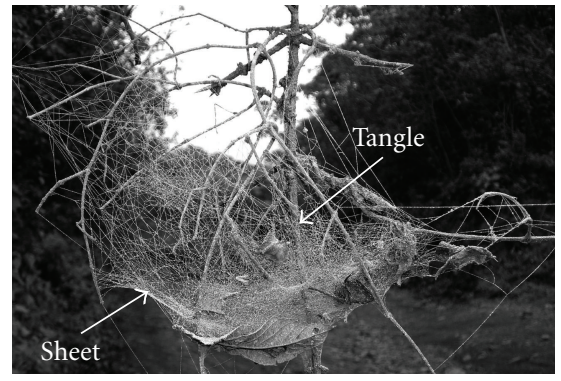

(a)

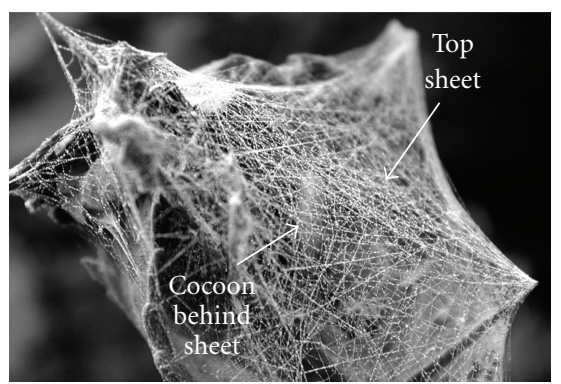

(c)

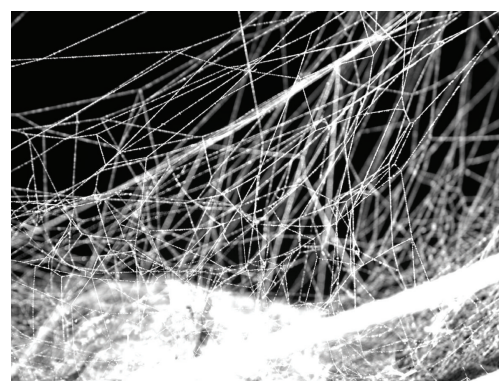

(b)

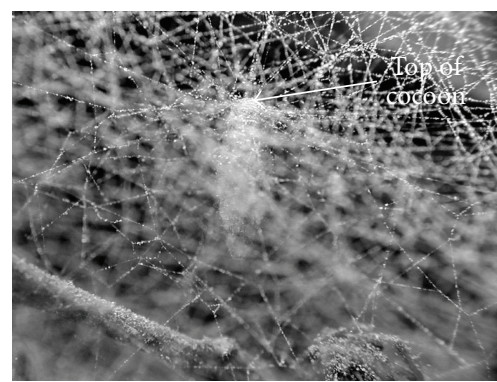

(d)

FigURE 1: Lateral views of an entire typical web of a nonparasitized mature female A. octavius (a) and a closeup view of the tangle (b). Lateral views of a cocoon web of $A$. nr. studiosus with a sheet enclosing the entire web (c), and of the central platform in the tangle of this web to which the upper portion of a wasp cocoon is attached $(d)$.

San Antonio de Escazú, and $1100 \mathrm{~m}$ el. in San Pedro de Montes de Oca (A. nr. studiosus), and at about $1650 \mathrm{~m}$ el. above Bebedero, Costa Rica (A. octavius). Cocoon webs with wasp cocoons built in the field were also collected intact, and examined under a dissecting microscope. Spiders in captivity were fed Drosophila sp. flies. Voucher specimens are deposited in the Museo de Zoología of the Universidad de Costa Rica (MZ) and the U. S. National Museum (spiders), and in the MZ and the Museum of Natural History, London (wasps). At each field site one of the two spider species was much more abundant than the other.

\section{Rersults}

3.1. Normal Webs. The webs of nonparasitized individuals of both A. studiosus and A. octavius were indistinguishable, and resembled those of other solitary Anelosimus species [17] in having a dense, somewhat concave sheet of irregularly oriented lines at the bottom of the web, and a moderately sparse tangle of lines above this sheet (Figures 1(a) and 1(b)). The degree to which the sheet extended upward at the edges varied; in extreme cases it formed a deep cup. Most webs were built near the end of a small branch. Many had leaves or other detritus in the tangle, and the spider hid under objects in the tangle during the day. Normal webs lasted for days and weeks at a time in the field, and were little damaged by moderate rain and wind.

3.2. Cocoon Webs. Seventeen cocoon webs were observed. Four in the field and one in captivity were made by
A. octavius; six in the field and six in captivity were made by A.nr. studiosus. In five cases the spider modified a web brought into captivity to produce a cocoon web, in all cases 1-2 days before the larva killed the spider. Two spiders abandoned their webs in captivity, and each built a complete cocoon web during the two nights before it was killed by the larva.

All cocoon webs in the field and all but one built in captivity were similar: the normal sheet was extended to enclose the entire web (Figure 1(c)); there was a small dense patch of more or less horizontal lines in the central portion of the tangle which had an approximately radial arrangement (Figures 1(d), 2(a), 2(c), and 2(d)); and just below this central patch there was a space that was free or nearly completely free of lines (Figure 2(b)). After completing the cocoon web: the spider rested at this exposed central area in the tangle during the day, instead of crouching as usual under a leaf or branch. The wasp larva then killed the spider, sucked its carcass dry and dropped it, and built a pupal cocoon attached at its upper end to the dense central patch of lines.

The exceptional web was built in captivity on the night of the same day the spider was collected (the field web sustained substantial damage when it was collected). The spider did not build a sheet over the tangle, but the tangle included a central area with a dense array of more or less radial lines and an open space below.

Of the two parasitized spiders that abandoned their previous webs in captivity, one built a small tangle on one night on a plant where it rested under a leaf, and then, on the night that the larva killed it, built silk sheets that joined the 


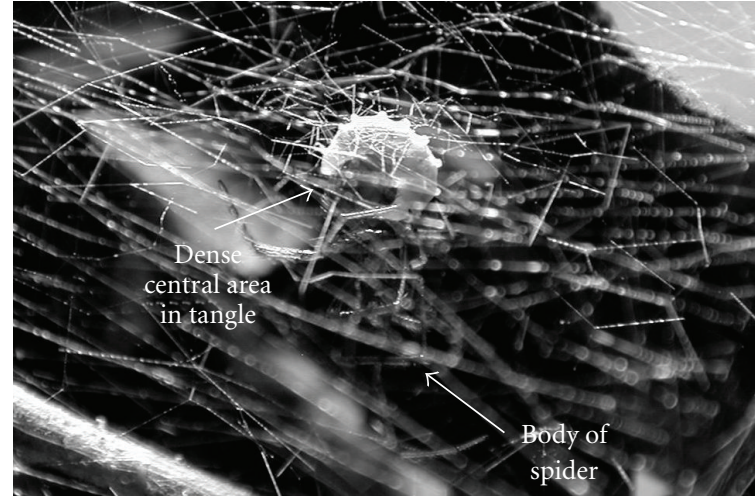

(a)

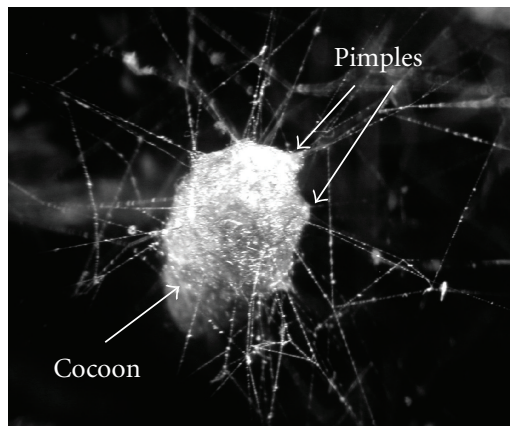

(c)

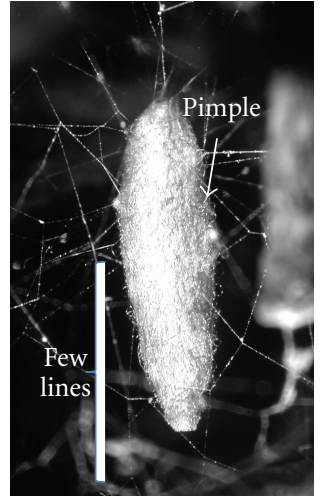

(b)

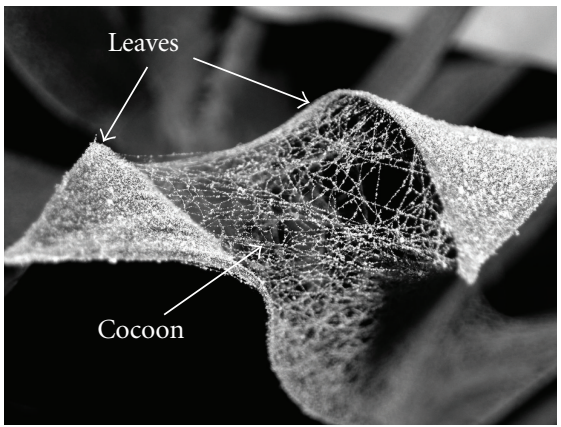

(d)

Figure 2: Cocoon web of $A$. nr. studiosus (a) in which the wasp larva holds onto the densely-meshed central area just after having discarded the corpse of the spider. Lateral (b) and dorsal (c) views of wasp cocoons in cocoon webs of A. octavius, showing the radial pattern of lines around the upper end of the cocoon (c), and that the lines intersecting the cocoon (indicated by small "pimples") are in the upper portion of the cocoon, with an open space below in which the cocoon hangs free (bar in (b)). The cocoon web spun from scratch in captivity (d) incorporated flat leaves (covered with white dust in the photo) as parts of the sheet.

two edges of this leaf to the leaf below, thus enclosing itself on all sides (Figure 2(d)). The other spider built a tangle and a sheet that completely enclosed the tangle on the first night, then added further lines to the sheet the next night before the larva killed it early the next morning.

One spider observed while building a sheet in a cocoon web alternated between working on the sheets above and below the tangle; making multiple successive attachments to other lines in each sheet. It hung under the upper sheet while it worked there, and walked on top of the lower sheet while adding lines there. Each of two spiders observed during the final stages of cocoon web construction (these spiders were dead and being consumed only 5 and $4.5 \mathrm{hrs}$ after observations ended) spent the entire time in a small section (about $2 \times 2 \times 4 \mathrm{~cm}$ ) in the central portion of the tangle, making forays downward and to the sides from the upper edge of this central volume and then returning to the central site. Each spider occasionally attached her dragline as she moved, and may have also broken lines; examination of one finished web revealed several lax, apparently broken lines in this area (and also a few in other parts of the web). Eventually the spider rested immobile at the central site, where the larva then killed and consumed it, and built its cocoon the next day.

\section{Discussion}

In all species of polysphinctine wasps known to modify the behavior of their web-spinning host spiders $[8-14,16]$, the manipulated spider performs fragments of behavior patterns that are used to build normal webs or retreats. In some spiders (Plesiometa, Allocyclosa, Agelena) these behavioral fragments are combined to produce structures that are apparently never produced by nonparasitized spiders [11], while in others (Nephila, perhaps Theridion) the resulting structures are at least somewhat similar to those of normal webs $[9,10]$. At least some behavior elicited by $Z$. nr. solanoi produced web designs resembling those of normal host webs. The tightly meshed sheet that encloses the web is an extension of the lower sheet present in normal webs, and the construction behavior of the two sheets did not differ perceptibly except for the spiders' orientation. However, a small platform in the tangle, with multiple radiating lines just above an open space, is not a recognizable component of normal Anelosimus webs. Breaking lines, which was used to open the space, may be part of normal web construction, as broken lines were also present at other sites in a newly built web.

The most surprising behavior in this study was that of spiders which built complete cocoon webs from scratch. The 
normal webs of Anelosimus generally last for many weeks, and spiders apparently only rarely change sites and build new webs, so wasp larvae are probably seldom called upon to induce the construction of an entire cocoon web from scratch. One of these webs employed large flat leaves to substitute for parts of the upper and lower sheets of the cocoon web (Figure 2(d)). Although further observations are needed, this flexibility suggests that the wasp larva may manipulate the spider at higher rather than lower levels in the hierarchy of behavioral control mechanisms.

Despite its close relation with $Z$. petronae, the behavioral modifications induced by $Z$. nr. solani are qualitatively different [10], thus following the pattern seen in other polysphinctine wasps, in which behavior modifications tend to be more closely adjusted to the natural history of their hosts than to the phylogenetic relations of the wasps [7].

\section{Acknowledgments}

The author thanks Gilbert Barrantes and Pablo Guitierrez for spiders wasp larvae, Ingi Agnarsson and Paul Hanson for identifying spiders and wasps, and STRI and the Universidad de Costa Rica for financial support.

\section{References}

[1] R. Poulin, "Manipulation of host behaviour by parasites: a weakening paradigm?" Proceedings of the Royal Society B, vol. 267, no. 1445, pp. 787-792, 2000.

[2] J. Moore, "Parasites that change the behavior of their host," Scientific American, vol. 250, no. 5, pp. 108-115, 1984.

[3] C. J. Barnard and J. M. Behnke, Parasitism and Host Behavior, Taylor \& Francis, London, UK, 1990.

[4] J. Brodeur and L. E. M. Vet, "Usurpation of host behavior by a parasitic wasp," Animal Behaviour, vol. 48, pp. 187-192, 1994.

[5] J. A. Harvey, M. Kos, Y. Nakamatsu et al., "Do parasitized caterpillars protect their parasitoids from hyperparasitoids? A test of the "usurpation hypothesis"', Animal Behaviour, vol. 76, no. 3, pp. 701-708, 2008.

[6] I. D. Gauld, J. A. Ugalde, and P. Hanson, "Guia de los Pimplinae de Costa Rica," Revista de Biología Tropical, vol. 46, supplement 1, pp. 1-189, 1998.

[7] I. D. Gauld and J. Dubois, "Phylogeny of the Polysphincta group of genera (Hymenoptera: Ichneumonidae; Pimplinae): a taxonomic revision of spider ectoparasitoids," Systematic Entomology, vol. 31, no. 3, pp. 529-564, 2006.

[8] W. G. Eberhard, "Spider manipulation by a wasp larva," Nature, vol. 406, no. 6793, pp. 255-256, 2000.

[9] M. O. Gonzaga, J. F. Sobczak, J. Vasconcellos-Neto, A. P. S. Loffredo, and A. M. Penteado-Dias, "The effect of host body size and web aggregation on parasitism of Nephila clavipes (Araneae, Nephilidae) by Hymenoepimecis bicolor (Hymenoptera, Ichneumonidae)," Ethology, Ecology \& Evolution, vol. 22, no. 2, pp. 151-165, 2010.

[10] J.-L. Weng and G. Barrantes, "Natural history and larval behavior of the parasitoid Zatypota petronae (Hymenoptera: Ichneumonidae)," Journal of Hymenoptera Research, vol. 16, no. 2, pp. 326-335, 2007.

[11] R. Matsumoto, “"Veils” against predators: modified web structure of a host spider induced by an ichneumonid parasitoid, Brachyzapus nikkoensis (Uchida) (Hymenoptera)," Journal of Insect Behavior, vol. 22, no. 1, pp. 39-48, 2009.
[12] W. G. Eberhard, "Under the influence: webs and building behavior of plesiometa argyra (Araneae, Tetragnathidae) when parasitized by hymenoepimecis argyraphaga (Hymenoptera, Ichneumonidae)," Journal of Arachnology, vol. 29, no. 3, pp. 354-366, 2001.

[13] E. Nielsen, "Contributions to the life history of the Pimpline spider parasites (Polysphincta, Zaglyptus, Tromatobia) (Hym. Ichneum.)," Entomologiske Meddelelser, vol. 14, pp. 137-205, 1923.

[14] R. Matsumoto and K. Konishi, "Life histories of two ichneumonid parasitoids of Cyclosa octotuberculata (Araneae): Reclinervellus tuberculatus (Uchida) and its new sympatric congener (Hymenoptera: Ichneumonidae: Pimplinae)," Entomological Science, vol. 10, no. 3, pp. 267-278, 2007.

[15] W. G. Eberhard, "Recovery of spiders from the effects of parasitic wasps: implications for fine-tuned mechanisms of manipulation," Animal Behaviour, vol. 79, no. 2, pp. 375-383, 2010.

[16] M. O. Gonzaga and J. F. Sobczak, "Parasitoid-induced mortality of Araneus omnicolor (Araneae, Araneidae) by Hymenoepimecis sp. (Hymenoptera, Ichneumonidae) in southeastern Brazil," Naturwissenschaften, vol. 94, no. 3, pp. 223-227, 2006.

[17] W. G. Eberhard, I. Agnarsson, and H. W. Levi, "Chaos from order: the evolution of web designs in theridiid spiders (Araneae, Theridiidae)," Systematics and Biodiversity, vol. 6, pp. 1-61, 2008. 

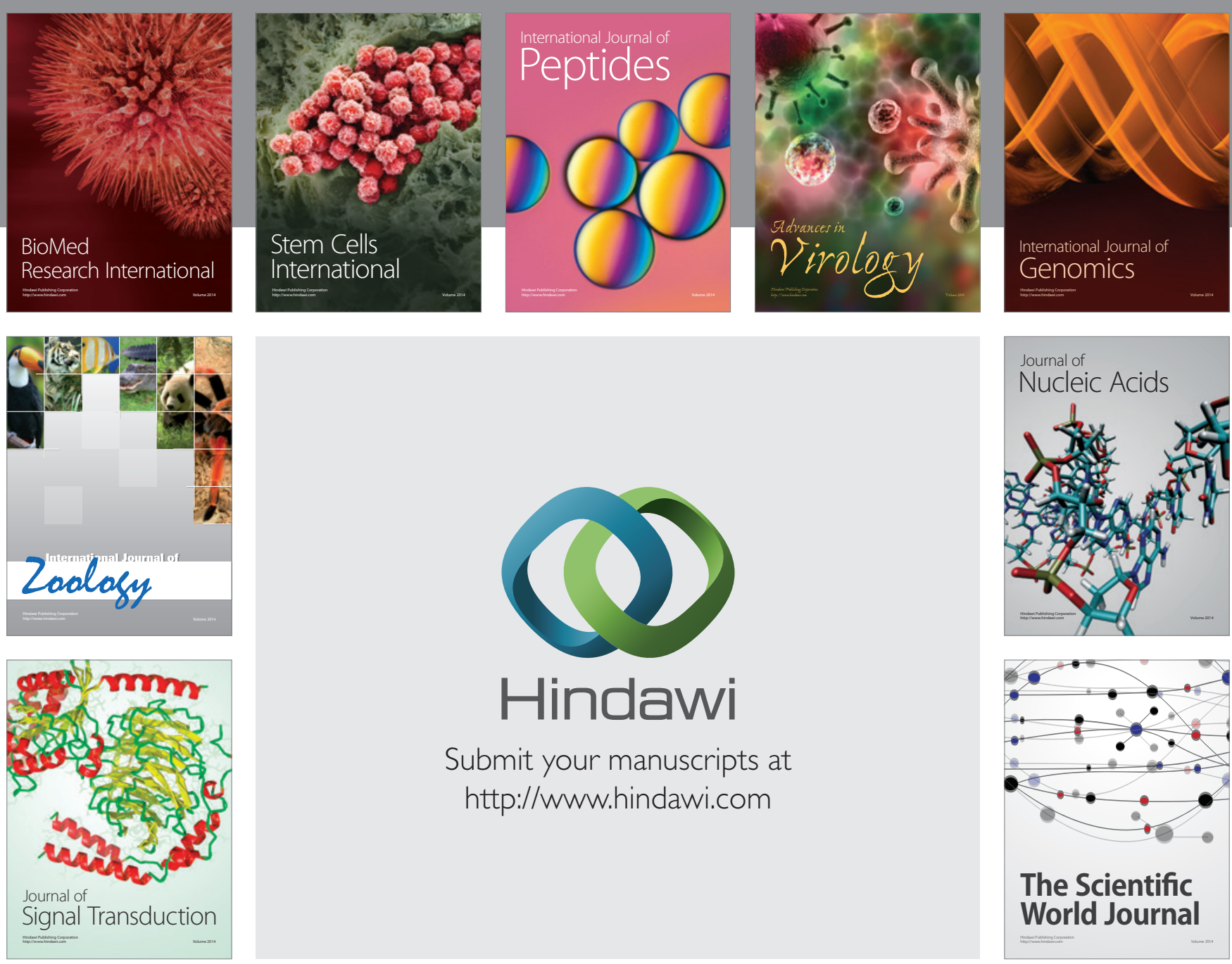

Submit your manuscripts at

http://www.hindawi.com
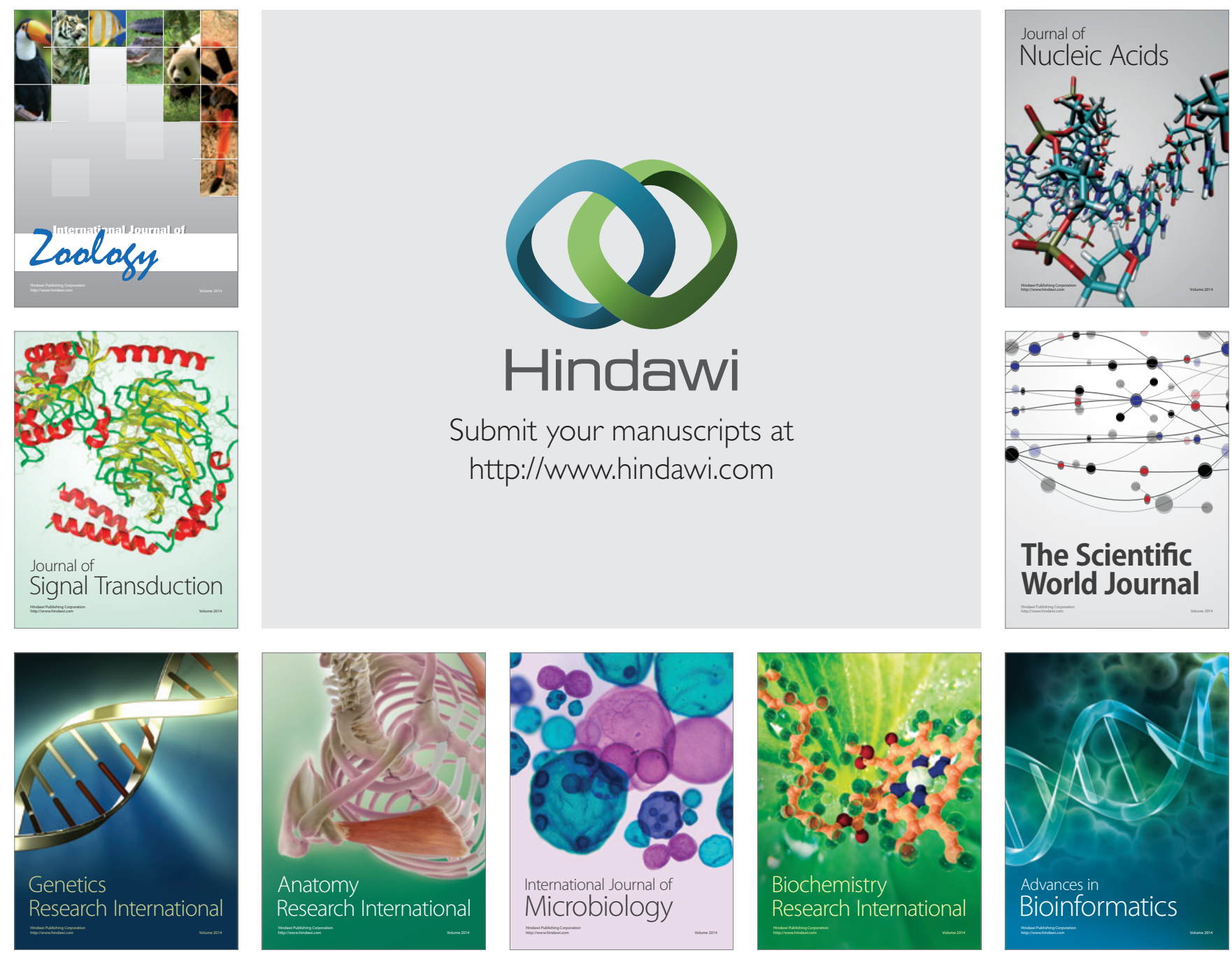

The Scientific World Journal
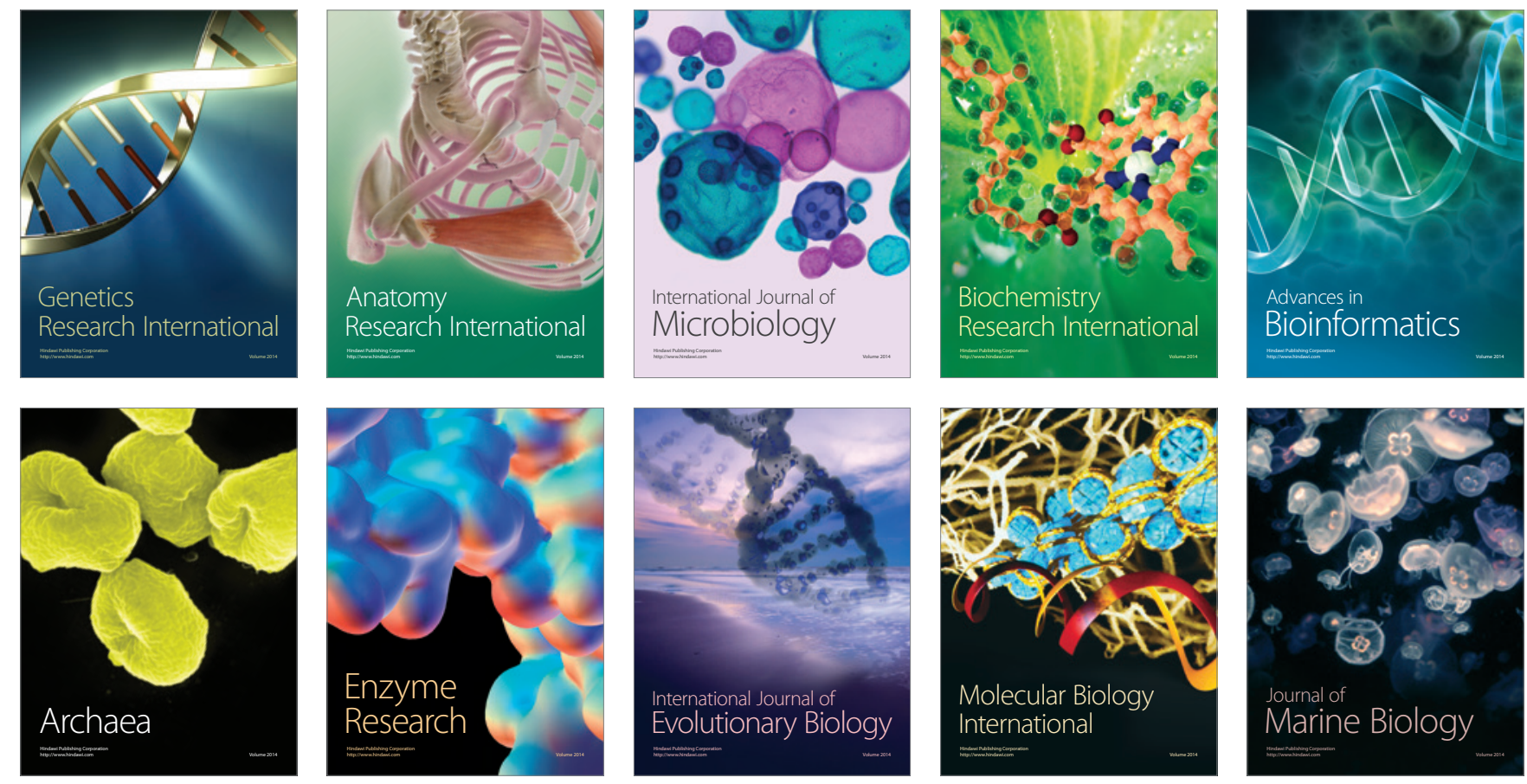